\title{
Problem-solving Software
}

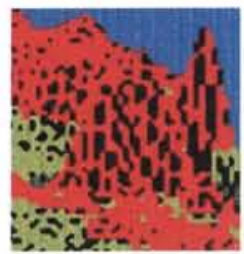

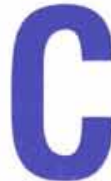
ase-based reasoning $(\mathrm{CBR})$ is defined as "a problem-solving paradigm that adapts stored problem solutions - or cases - to solve new problems specified by a user." CBR is applicable to a wide range of classification and construction tasks. It is particularly useful in tasks where a formal set of rules for generating solutions is difficult to obtain, but examples of correct solutions to similar problems are readily available.

Inference Corporation, El Segundo, California has introduced a stand-alone commercial software product based on CBR.

Known as CBR Express ${ }^{\mathrm{TM}}$, it EMERGED FROM NASA SOFTWARE DEVELOPMENT
A COMMERCIAL PROBLEM-SOLVING PRODUCT incorporates technology originally developed by Inference in work on the
Advanced Software Development

Workstation (ASDW) for Johnson Space Center (JSC). Shown below are the three members of the company's original CBR design team, from left, Elizabeth Ralston, Daniel Lee and David Lee.

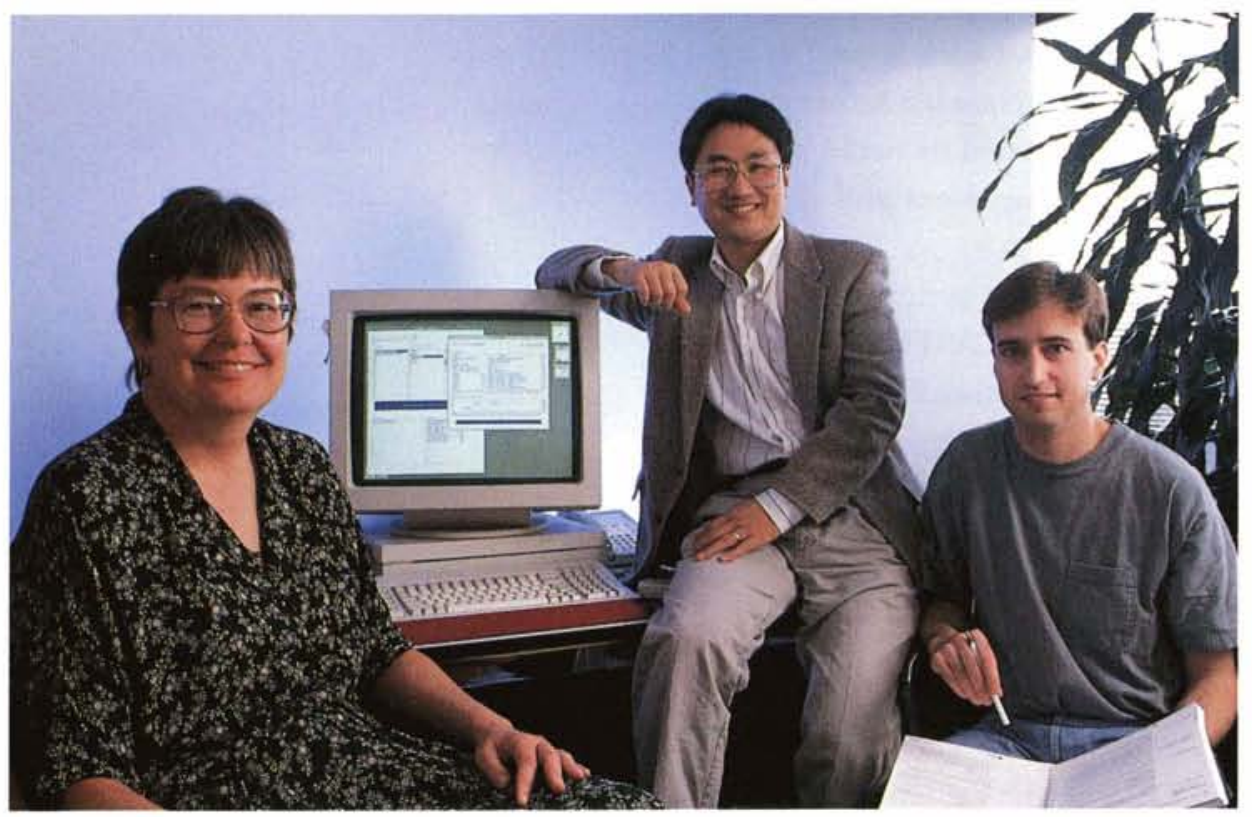

The JSC project focused on reuse of software designs and software components as a means of reducing costs and relieving a bottleneck in software development and in maintenance of deployed systems. Software reuse involves the retrieval and modification of existing software components. The method used was a knowledge-based system that provided a software parts composition system, which consists of a language for modeling software parts and their interfaces; a catalog of existing parts; an editor for combining parts; and a code generator that takes a specification and generates code for that application in the target language.

In the ASDW project, Inference Corporation employed CBR in the reuse process as part of the ACCESS prototype software. ACCESS is a knowledge-based software information system designed to assist the user in modifying or configuring retrieved software or design objects to the user's specifications.

The commercial CBR Express that emerged as a spinoff from the ASDW project is used as a "help desk" for customer support, enabling reuse of existing information when necessary. It has been adopted by a number of companies, among them American Airlines, GTE Corporation and Nippon Steel. An example of its utility: if American Airlines' reservation system software did not work, CBR Express would solve the problem by identifying similar problems in its database; essentially it classifies a given problem situation on the basis of past problems.

TMCBR Express is a trademark of Inference Corporation. 